
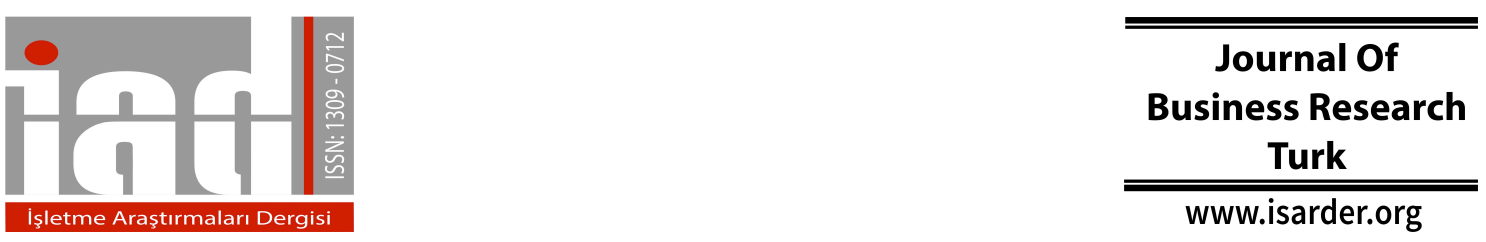

\title{
N-Gram Analysis of Historic Development of Fundamental Terms Regarding Corporate Sustainability ${ }^{1}$
}

\author{
Özlem TUNA \\ Afyon Kocatepe University \\ Afyon Health School, \\ Health Facilities Management \\ Afyonkarahisar, Turkey \\ orcid.org/0000-0002-5842-7889 \\ ozltuna@hotmail.com
}

\author{
M. Nuri URAL \\ Gumushane University \\ Faculty of Engineering \\ Software Engineering \\ Gümüşhane, Turkey \\ orcid.org/0000-0001-7011-401X \\ mnu23@yahoo.com
}

\begin{abstract}
Sustainability is a rising concept. It is important to set forth the development process of the term and to reveal the topics which are stressed by the specialists in order to understand the concept correctly. With this study, all the books written in English and saved in 'Google Books' database starting from the 1900s to the recent years have been scanned with $\mathrm{N}$-gram analysis and the evolution of corporate sustainability concept has been investigated. From 19 experts 15 key words about corporate sustainability were asked. Total 236 entries have been categorized in 62 themes and among them 17 keywords which have the highest frequencies were identified and used in N-gram analysis. This study is especially important to show which term is started to flourish on literature on which time period. It is meaningful that some terms show co-changes. This may be helpful to show the relations between these terms.
\end{abstract}

Keywords: Corporate sustainability, sustainability development, corporate social responsibility, N-gram, retrospective analysis, time line analysis.

\section{Introduction}

Sustainability is a rising concept. Modern establishments have started to give prominence to studies on sustainability in their activities, supply chain relationships and investment decisions due to reasons such as economic profitability concerns, investor and public pressure, increasing reputation, ensuring sustainable competitive advantage and the obligation to observe legal regulations. Many international organizations are in agreement that growing issues such as climate change, depletion of natural resources and human rights violations should be resolved as soon as possible for long term development and stability, and the solution to these issues shall be possible as establishments increase their applications in environmental, social and corporate

\footnotetext{
${ }^{1}$ This study is partial presented on November 2015 "International Conference on Sustainable Development- ICSD 2015" in Belgrade Serbia.
} 
management arenas. This sensitivity started to increasingly engage senior managers of establishments; shaped consumer expectations and other market drivers; and gave momentum to investments of establishment in this area. These developments have led sustainability to become an integral part of strategies and activities of establishments in the new world order where business interests do not conflict with social conflicts, and where social and environmental issues are also important besides economic and profitoriented point of view.

Sustainability, the origins of which lie in the Latin term of "subtenir," means to "protect" or "support from below" (Muscoe, 1995) and the term goes back to the industrial revolution. Mass production that increased with the industrial revolution caused excessive consumption of natural resources, which led to the disturbance of ecological balance. Although societies obtained economic growth by achieving their industrialization objectives, they were not able to prevent occurrence of environmental and social issues during this period. These negativities made it necessary to take certain measures in order to ensure sustainability of economic development. Studies intended for developing environment and social surroundings at the same time as economic growth caused the term of sustainable development to emerge. The contribution of real industry in fulfilling necessary conditions for sustainable development was defined as corporate sustainability.

There are many researches since the beginning of the concept sustainability. The researchers inspected the subject from different perspectives. Many researches focus on social and environmental relations as some of them inspected the economic performance. (Griffin and Mahon, 1997; Stanwick and Stanwick, 1998; Waddock and Graves, 1997). Although there are many researches that show positive relation between corporate sustainability and economic performance the issue is not certain yet. Besides by methodological studies there is no evidence which show how the environmental and social performance is effecting the economic performance (Hahn and Scheermesser, 2006). There is almost a consensus about the factors building corporate sustainability and about the best way how to apply it (Besler, 20019). There are a series of attitudes from choosing products and processes to limit source usage and environmental pollution to improve the relations with the society or the stakeholders (Crane, 2000; GonzálezBenito and González-Benito, 2006).

With all this studies accomplished the concept of corporate sustainability has been outlined in social, economic and environmental outline. But there is still a need of improvement of the understanding of the term. To improve this understanding the development process of the term and the topics which are stressed by the specialists may be investigated in order to understand the concept correctly.

In this study, the whole library of Google on books.google.com website was reviewed using the n-gram reviewing interface, which was provided also by Google. The mentioned library contained more than 25,000,000 books as of October 2015. Such books were reviewed from 1900s to 2008 as far as Google n-gram interface permitted.

$\mathrm{N}$-Gram is a statistical analysis technique utilizing the repetition frequency of a certain number of substrings in a set of characters. N-grams of texts are extensively used in text mining and natural language processing tasks. This technique provides information on repetition rates of substrings in areas such as sequential analysis in the fields of probability, communication theory, natural language processing or 
computational biology (Manning and Schütze, 1999). Furthermore, this application enables obtaining different analysis results using many different analysis parameters in a wide range of fields.

For example, for the pangram "jackdaws love my big sphinx of quartz"; if $n=2$ (known as bigrams) then the n-gram analysis would result:

1. jackdaws love

2. love my

3. my big

4. big sphinx

5. sphinx of

6. of quartz

So in this case we would have 6 bigrams. For $n=3$ the n-grams would change

1. jackdaws love my

2. love my big

3. my big sphinx

4. big sphinx of

5. sphinx of quartz

So as seen on the list above there would be 5 trigrams $^{2}$.

So if a long text, like a book, is divided into substrings and n-gram frequencies are determined we can calculate a percentage for each n-gram.

$$
\text { Percentage }=\frac{\text { The frequnecy of a specific } n-\text { gram }}{\text { Total count of } n-\text { grams }}
$$

Although there are many open source algorithms for n-gram analysis, for this study an interface by google has been used. The Google N-Gram Viewer application was used only at a very fundamental level for this study. N-Gram Viewer interface was used during the study to carry out relative comparison of mentions of fundamental terms concerning corporate sustainability in books in the database of Google. Thus, the repetition frequencies of terms and / or term groups in the literature were determined. Researchers suggest that the repetition frequency of a term in the literature is an indicator of the importance attributed by individuals that are interested in such term in scientific terms. Furthermore, the analysis, emergence times of such terms, as well as increases and decreases of their utilization frequencies in years enables us to obtain information on the variation of relative ratios of utilization frequencies of associated terms.

It is considered that the study provides a different analysis technique and an extraordinary perspective in terms of corporate sustainability. It is thought that the data collected by the study will assist in formation of solid foundations based on quantitative data intended for social perception of terms regarding corporate sustainability.

\section{Conceptual framework}

Industrialization, which started at the end of 18th century, created a boom in the amount and variety of pollutants released into the atmosphere, while the failure to take any action to contain pollution resulted in the emergence of heavy pollution and

\footnotetext{
${ }^{2}$ For a single word it would be called unigram and for $\mathrm{n}>3$ it would be called four grams, five grams etc.
} 
environmental degradation (Ponting, 2008). Mass production, which increased with industrial revolution as well, caused excessive consumption of natural resources, which led to the disturbance of ecological balance. Although societies achieved their industrialization objectives and ensured growth in this period, they were unable to prevent the emergence of environmental and social issues. These negativities made it necessary to take certain measures in order to ensure sustainability of economic development. Studies intended for improving environment and developing social surroundings at the same time as economic growth assisted in the emergence of the term of sustainable development (Tuna, 2014: 1). Developments toward sustainable development since Carl Von Carlowitz (1713) show that sustainable development has developed essentially as an environmental approach. Later on, development models, which would embody economic and social matters to balance intra- and intergenerational needs, were developed (Tiryakioglu and Tuna, 2016: 209). The studies that have approached the environmental aspect of sustainability since 1960s focused on the issues of air and water pollution, depletion of natural resources such as petroleum reserves and forests (Carson, 1962) and overpopulation (Ehrlich, 1968); while studies carried out in the following years (Meadows et.al., 1972; Vitousek et. al., 1986; Norgaard, 1994) continued to support the environmental aspect of the term. On the other hand, socially sustainable development addressed the titles of securing close social relationships between societies or, in a broader sense, protecting societies (Repetto, 1986: 609), ensuring political responsibility and participation, supporting gender equality, achieving a sufficient level of social services in terms of education and health, and equal distribution of production (Haris, 2000: 5-6). Many studies (Streeten et al., 1981; Porter and Sheppard, 1998; Haugh and Talwar, 2010) have been carried out concerning the social aspect of sustainable development particularly since 1980s.

During 1990s, developments in the sense of management and corporate social responsibility (CSR) resulted in the emergence of the sense of corporate sustainability with environmental, social and economic aspects during the process. (Young and Tilley, 2006: 403).

The term of sustainability is a field that has been heavily studied and that is still blooming despite the long period that has passed since its initial use. The most suitable resource that can be referred in order to achieve an understanding of the field is literature. Repetition frequency of key terms regarding corporate sustainability in the books in English, provided by 'Google books', can assist in identification of points concerning corporate sustainability that were emphasized by experts in the field.

\section{Materials and Methods}

The main objective of the study is to identify repetition frequencies of corporate sustainability and fundamental terms that assist the development of corporate sustainability by years, with the help of N-Gram Viewer application. This study intends to obtain answers for the following questions:

- What are the opinions of field experts on what the most fundamental terms regarding sustainability are?

- To what extent are these terms regarding sustainability mentioned in the literature? 
- When did these terms regarding sustainability start to emerge and, so, gain importance in the literature?

- What is the variation over time of frequencies, with which those terms, having emerged in similar time frames, were encountered in the literature?

Expert opinions were received in order to identify key terms to be used during the study following the literature review conducted in line with this objective. E-mails containing details on the study and requesting their participation in the study were sent to 25 individuals, who were academics and business people with expertise on corporate sustainability. The answers were arrived from June to August 2015. A total of 10 field experts, 7 of who are academics and 3 of which are mid-level and senior executives in charge of sustainability activities of private sector establishments where they work, responded positively to the mentioned request. Although each participant was asked to provide 15 key terms, a total of 137 terms could be obtained from ten participants instead of 150. Among the academics, 2 were professors, 4 were associate professors and 1 had a $\mathrm{PhD}$ degree without a title. Participants that were working in private sector were sustainability department executives of companies operating in major appliances, metal and automotive industries. All of the participants had postgraduate degrees. Data were obtained from a total of five female and five male participants including four male and three female academics, as well as two female and one male private sector participant.

Collected data were analyzed and presented during 2016 ICSD Congress (Ural and Tuna, 2015). However, in order to be able to improve the study, which was conducted on 10 individuals, because of the researchers difficulties in collecting data, it was decided to collect additional data from 12 participants of ICSD. Here, 9 individuals responded positively and new data were obtained. Among 9 participants, 9 were associate professors, 2 were assistant professors, and 1 was research assistant, while 2 held executive positions in private sector. These new data were combined with previously obtained data and a new analysis was conducted from a different perspective. New terms were obtained taking advantage of the experience obtained from the previous study, terms were re-categorized and the frequency of repetition of each category by participants of the study was determined. Two experts from the field conducted independent analyses in line with determined categories. A common opinion was agreed upon and its validity and reliability was ensured in line with the comparisons. After that the most recurring terms among such determined terms were initially subjected to n-gram analysis on an individual basis, and dates of their first emergence in the literature were determined. Obtained list was ranked according to the date of emergence. The mentioned list can be found in Table 1. 
Table 1: Dates When Obtained Terms Initially Emerged in the Literature

\begin{tabular}{|c|l|c|c|l|c|}
\hline $\begin{array}{c}\text { Theme } \\
\text { Order }\end{array}$ & Themes & Years & $\begin{array}{c}\text { Theme } \\
\text { Order }\end{array}$ & Themes & Years \\
\hline 1 & social development & 1800 & 13 & sustainable development & 1970 \\
\hline 2 & economic development & 1870 & 14 & sustainable management & 1970 \\
\hline 3 & business ethics & 1870 & 15 & biodiversity & 1980 \\
\hline 4 & environmental development & 1890 & 16 & $\begin{array}{l}\text { environmental } \\
\text { sustainability }\end{array}$ & 1980 \\
\hline 5 & recycle & 1920 & 17 & social sustainability & 1980 \\
\hline 6 & organization culture & 1920 & 18 & economic sustainability & 1980 \\
\hline 7 & waste management & 1940 & 19 & eco efficiency & 1980 \\
\hline 8 & corporate social responsibility & 1950 & 20 & green marketing & 1980 \\
\hline 9 & social entrepreneurship & 1950 & 21 & eco design & 1990 \\
\hline 10 & environmental management & 1960 & 22 & triple bottom line & 1990 \\
\hline 11 & corporate governance & 1960 & 23 & green urbanism & 1990 \\
\hline 12 & $\begin{array}{l}\text { sustainable (green - } \\
\text { environmental) accounting }\end{array}$ & 1970 & 24 & corporate sustainability & 1990 \\
\end{tabular}

24 terms from a total of 61 terms, which were determined as a result of coding 236 terms received from 19 participants, were included in the study. These terms are ones that were the most frequently mentioned by the participants. In order to limit the study, the researchers included determined terms with a repetition frequency of 5 and above in the study, while those below 5 were excluded from the study, as their frequencies were not sufficient. The terms included in the study and their frequencies can be found in Table 2. Terms such as social capital, corporate reputation, footprint, and innovation management were mentioned by the participants; however, they were not included in the study, as they did not achieve sufficient frequency.

Table 2: Frequency of Terms

\begin{tabular}{|c|c|c|c|c|c|}
\hline $\begin{array}{l}\text { Theme } \\
\text { Order }\end{array}$ & Themes & Freq. & $\begin{array}{l}\text { Theme } \\
\text { Order }\end{array}$ & Themes & Freq. \\
\hline 1 & green marketing & 18 & 13 & business ethics & 7 \\
\hline 2 & sustainable management & 17 & 14 & recycle & 6 \\
\hline 3 & corporate governance & 15 & 15 & economic sustainability & 6 \\
\hline 4 & environmental development & 14 & 16 & biodiversity & 6 \\
\hline 5 & environmental management & 11 & 17 & corporate social responsibility & 5 \\
\hline 6 & waste management & 11 & 18 & environmental sustainability & 5 \\
\hline 7 & social sustainability & 10 & 19 & social entrepreneurship & 5 \\
\hline 8 & eco design & 9 & 20 & social development & 5 \\
\hline 9 & eco efficiency & 9 & 21 & economic development & 5 \\
\hline 10 & sustainable development & 9 & 22 & triple bottom line & 5 \\
\hline 11 & green urbanism & 9 & 23 & corporate sustainability & 5 \\
\hline 12 & organization culture & 7 & 24 & $\begin{array}{l}\text { sustainable (green - } \\
\text { environmental) accounting }\end{array}$ & 5 \\
\hline
\end{tabular}

Retrospective analysis, which is a qualitative research method, was used during the study. Retrospective analysis, which is defined as retrospective impression, was conducted by reviewing fundamental terms regarding corporate sustainability, obtained by the researchers from books dating back to $1900 \mathrm{~s}$, registered in the database of 'Google Books', with N-gram Viewer application. N-gram review service, provided by Google, can be accessed via https://books.google.com/ngrams. Here, it is possible to 
conduct N-gram analysis on all books registered in the database on "Google books" (books.google.com).

Graph these comma-separated phrases: Albert Einstein,Sherlock Holmes, Frankenstein
between 1800 and 2000 from the corpus English $\square$ case-insensitive

Figure 1: Google N Viewer Interface

On this interface provided by Google, words to be searched are written in the first textbox. The checkbox near the textbox is intended for whether the search will be case sensitive. The first numeric value to be entered in the textboxes at the beginning of the following line specifies 'from' value (beginning date) of the time interval, while the second one specifies 'to' value (ending date). Language selection can be made with the pull-down menu near this section. The last setting that can be made before clicking on the search button labeled "Search lots of books" is the determination of smoothing factor. This factor enables the reduction of excessive peaks and bottoms on the graph drawn according to keywords. While it is possible to make more complicated searches by using different operators for the phrase to be searched, these features are beyond the scope of the conducted study.

As N-gram analysis is expressed in proportional values, the increase in the number of academic studies carried out in the last century does not affect the graphs obtained in the study. The reason for this is that our study takes the rate of repetition into consideration, instead of the repetition number of terms. Created graphs were used in the study by taking screenshots. Where a graph of multiple terms was created, it became harder for certain terms to be read on the graphs as they had relatively very low frequencies. In order the render the graph more legible, such terms on graphs were multiplied with a fixed coefficient and then reflected onto the graph. It was attempted to select the same coefficient and its powers for all terms to the highest possible extent, so that all terms on the graph would be equally legible. Coefficient effect should be taken into consideration when reviewing these graphs.

Analyses, conducted by means of the interface prepared by Google, were made in June 2016. While the N-gram analysis was conducted, terms that were intended to be on the same graph were separated with commas in the interface provided by Google, and lowercase was used for all terms. Beginning year of the review was entered as 1800 , ending year was entered as 2015, language was selected as English and smoothing factor was selected as 2. Case sensitivity box was left empty. Terms to be included in the review were categorized by means of the historical list that displayed in Table 1. Terms were categorized into a total of 5 historical periods; comprising of one group for pre-1920, one group for 1920 to 1960, one group for 1960 to 1980, one group for 1980 to 1990 , and one group for post-1990. While such categorization was made, emphasis was placed on having each period include a number of terms that were not close to each other and that would not negatively affect the legibility of graph. Relevant graphs can be found below.

As repetition frequencies certain terms were very low in the graphs, such graphs were created again in case their time-dependent decreases and increases close to zero 
level could not be observed. Thus, it was attempted to obtain legible graphs containing all terms, where time-dependent increases and decreases could be conveniently observed. These graphs on Google interface were copied with the screenshot tool provided by Windows 8 , and pasted on the text editor where this report was prepared. Then, these graphs were interpreted and the report was finalized.

M. Nuri URAL participated in the study by contributing to the design of the research procedure, identification of the research method, performance of works on Excel environment, as the N-gram analysis method expert and performer, as well as by obtaining and interpreting graphs, and by reporting all these actions.

Özlem TUNA contributed to the study as an expert in the field of corporate sustainability, by collecting data, by establishing theoretical foundations regarding sustainability with the help of the literature, by associating graphs with historical development of corporate sustainability, and by reporting all these actions.

Limitations of the study can be listed as the inability to include printed literature and being limited to books in English registered in 'Google Books' database from the year 1900 until the most recent date allowed by N-gram Viewer interface; limitation of key terms regarding corporate sustainability with the terms obtained from the opinions of 19 experts; and the utilization of only $\mathrm{N}$-gram viewer application for $\mathrm{N}$-gram analysis of Google Books database.

\section{Results and Discussion}

The terms obtained in line with the data received from the participants were analyzed by means of $\mathrm{N}$-gram analysis interface of Google. Accordingly, graphs were created in consideration of the literature regarding terms and responses received from the participants.

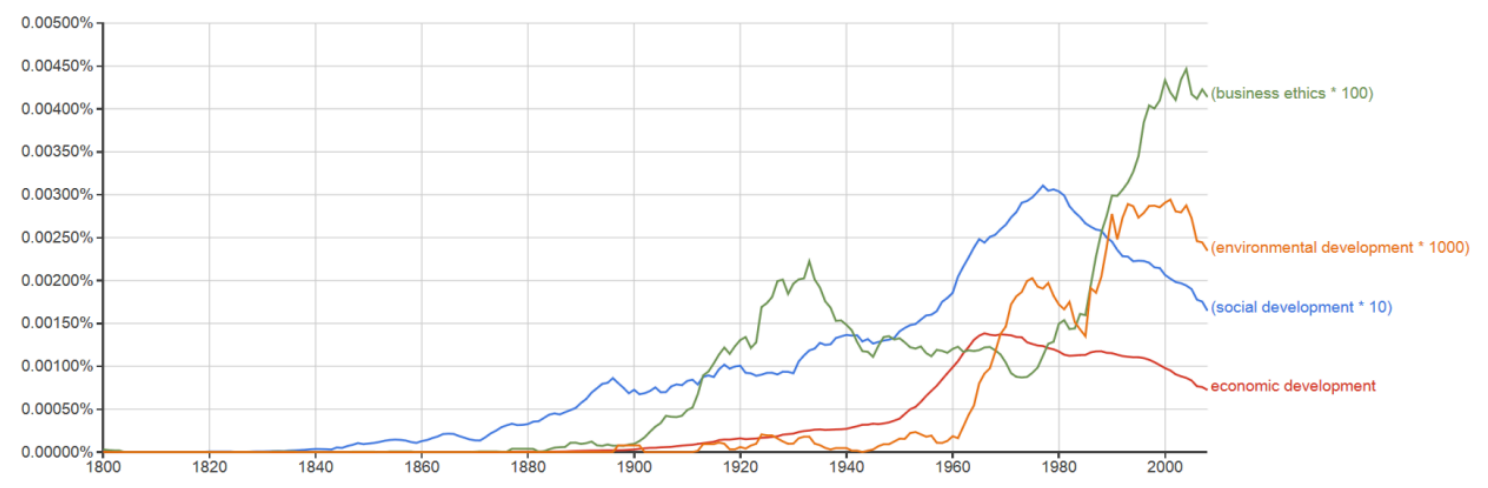

Figure 2: Variation of Terms That Emerged Before 1900 Over Time

Figure 2 shows the variation of four fundamental terms, which started to take place in the literature before 1900, over time as a result of classification of the data obtained from the participants. When the graph was created, amplified graphs were provided by multiplying environmental development, which had the lowest values, by 1000; business ethics by 100; and social development by 10 without multiplier in order to approximate all terms on the graph and ensure the highest legibility on the graph. Accordingly, it can be said that the term that is most frequently mentioned in the literature is economic development, which did not need any multiplier. Then, according to the frequency of being available in the literature, the last and the least encountered 
terms are respectively social development, business ethics and environmental development.

When the terms in the graphs are individually addressed, it is seen that business ethics term reached a peak in 1930s, had a decline from 1930 to 1975 but displayed a rapid upward trend from 1975 to 2008. Social development used to be in an upward trend until 1980s but it started to decline after 1985. Economic development displayed an upward trend until 1950s and increasingly continued such trend from 1950 to 1965 , while it started to decline after 1965. Environmental development, a term that is rarely encountered in the literature, displayed an uneven trend until 1960s, a rapidly increasing trend from 1960 to 1975, significantly declining trend from 1975 to 1985, rapidly increasing trend until 1990, and protected its status in a narrow band with an uneven trend from 2000 to 2008 .

Social development seen in Figure 2, which is a term that draws attention with its variation over time, has found its way into the literature and displayed an upward trend since 1840s. This can be interpreted as an indicator that the term is not only relevant to sustainability. 'Social development' was initially used by sociologists and anthropologists at the end of 19th Century, and it was defined as "a transitional stage from a primitive or traditional status to a modern status at a more advanced level" (Midgley, 2013: 4). Therefore, it can be said that the term is differentiated from other terms regarding sustainability. The transformation of social development into what we understand today occurred thanks to its re-definition in $1980 \mathrm{~s}$ by international development organizations such as United Nations Children's Emergency Fund (UNICEF), United Nations Development Program (UNDP), International Labor Organization (ILO) and World Bank in a sense of social state.

Another term that draws attention in Figure 2 is business ethics, which displayed an upward trend beginning from 1900s. The reason for such increase can be associated with different developments. The reasons for which business ethics gained importance can be listed as the extension of approach to the term beyond religious view by the end of the 19th century, criticism against excessive profit motive of capitalism, inequalities in distribution of prosperity, negative effects of industrialization on employees, emergence of business administration as an occupation, and acceptance of administrative science as a discipline. Furthermore, 'Watergate' scandal experienced in American politics in 1970s, as well as the increase in the number of major companies operating on international platform and the domination of private sector brought business ethics forward in a more prominent way (TUSIAD, 2009: 45-47). This effect was reflected on the graph as a rapid increase after 1960.

The decline of environmental development, social development and economic development, which are the three dimensions of sustainable development provided in Figure 2, in the recent decades can be attributed to substitution of these terms with a multitude of new terms (such as triple bottom line, social sustainability). Numeric data on these new terms can be seen in the following graphs. 


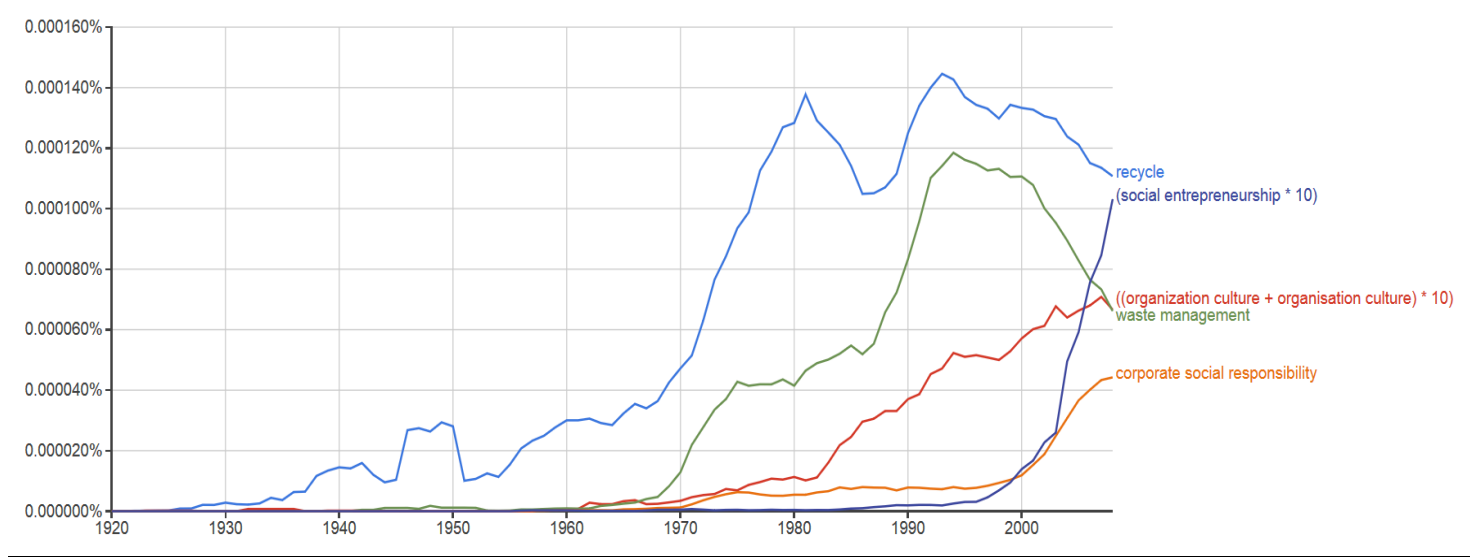

Figure 3: Variation of Terms Emerging From 1900 to 1960 Over Time

Figure 3 contains terms that emerged and developed from 1900 to 1960 . While recycle, waste management and corporate social responsibility (CSR) were included in the graph without any multiplier; organization culture and social entrepreneurship, which have much lower values than these three terms, were included in the graph by being multiplied with 10 .

When the frequency variation of recycle is examined by years, it is observed that the increase seen in the frequency of the term continued by gaining speed until 1983. Following a few years of decline, a new increase was experienced after 1993 and then the term went into a downward trend again. Waste management also had an upward trend until 1993 and then it went into a downward trend like recycle.

Literature presence frequencies of corporate social responsibility (CSR) and social entrepreneurship terms display similar trends over years. There have been slow increases in the terms until 2000s, while such increase gained speed after 2000. In the mid-1990s, the global communications capabilities of the internet and related technologies improved the power of institutions to create new pressures on companies to foster greater CSR. At that time more than half of corporations' assets were already found not in tangible but rather in intangible assets such as goodwill, reputation, and human capital, which increase the importance of CSR. At that time, CSR was also coupled with strategy literature and its relationship with market outcome was made more explicit. Besides, to study the changes in the relationship between business and society, in 1995 many researchers adopted the stakeholder theory (Moura-Leite; Padgett, 2011: 534).

The term social entrepreneurship started to be popular and have an upward trend when William Drayton, the first person who used the term, found 'Ashoka' to finance social entrepreneurs in 1980's. ${ }^{3}$. Then the number of papers, special issues of academic journals, workshops and conferences is constantly augmenting and a recent count found over 350 professors teaching and researching social entrepreneurship in more than 35 countries, and a 750\% increase in publication during the period 1991-2009 (Braunerhjelm and Hamilton, 2012:3). The interest to this concept at this time period is obvious on Figure 3.

\footnotetext{
${ }^{3}$ http://ashokau.org/ (Erişim tarihi: 02.11.2017)
} 
Another point that draws attention in the graph is the 'recycle' term that emerged in 1920s. Recycle has been important for mankind since the early ages of history. However, the most important development was observed with the industrial revolution. Then, the shortage of raw materials increased the interest in 'recycle' particularly during the 2nd World War. The upward trend of recycle curve in the post-1950 era supports this argument in the graph. Waste management also had a similar course as recycle. Terms went into a decline after 1993. The decline in these terms can be attributed to the emergence of terms such as zero waste, integrated waste management, and sustainable waste management, which emerged in almost the same period.

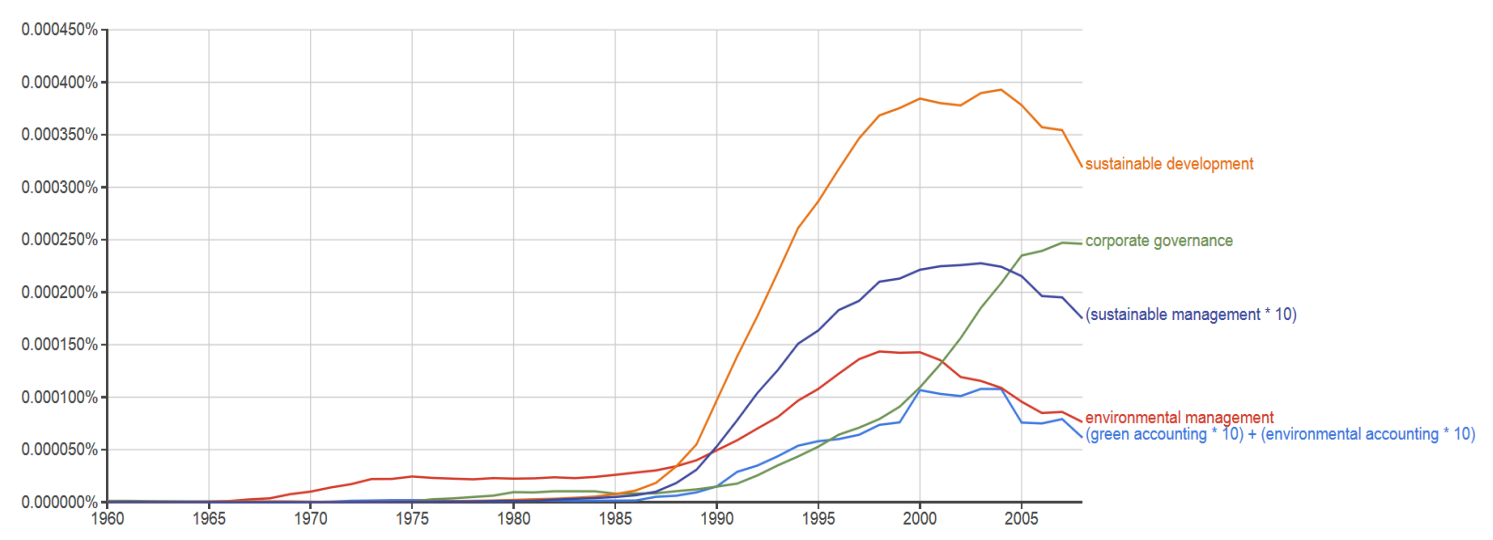

Figure 4: Variation of Terms Emerging From 1960 to 1980 Over Time

Terms that emerged in relation to corporate sustainability from 1960 to 1980 and the trend of these terms over years can be seen in Figure 4. In this graph, sustainable development, corporate governance and environmental management were included in the graph without using any multiplier, while sustainable management and green / environmental accounting terms were multiplied by 10 to increase legibility of the graph. All terms used to take place in the literature at very low levels until 1987, while there was a significant increase in all terms after 1990.

Sustainable development term experienced its highest period from 2000 to 2005, and then went into a decline from 2005 to 2008. The graph of sustainable management resembles sustainable development a lot; the only difference is that the curve is flatter.

Environmental management and green / environmental accounting terms also displayed similar changes at a remarkable level. There was a slight difference only in the years and levels that these two curves reached their peaks.

Another very interesting trend on Figure 4 is the corporate governance concept. The term has emerged in the USA, the Securities Exchange Commission, the New York Stock Exchange, and the Roundtable, among others, have continued to issue codes since the late 1970s. However, it was not until a decade later that another country created a code of good governance. In 1989, the Hong Kong Stock Exchange issued its first 'Code of Best Practice, Listing Rules', and in 1991 the Irish Association of Investment Managers drafted the 'Statement of Best Practice on the Role and Responsibility of Directors of Publicly Listed Companies'. Nevertheless, the development of codes grew rapidly in the early 1990s, following the 1992 'Cadbury Committee Report: Financial Aspects of Corporate Governance' in the UK (Aguilera and Cuervo-Cazurra, 2004: 420421). After that in 1999 OECD has published the corporate governance principals and 
after the scandals such as Enron and WorldCom in 2002 The Sarbanes Oxley law has been legislated in USA. Those may be the cause for rising popularity of the concept after 90's.

Corporate governance term general trend is differentiated from sustainable development, sustainable management, environmental management and green / environmental accounting terms, trends of which are very similar to each other.

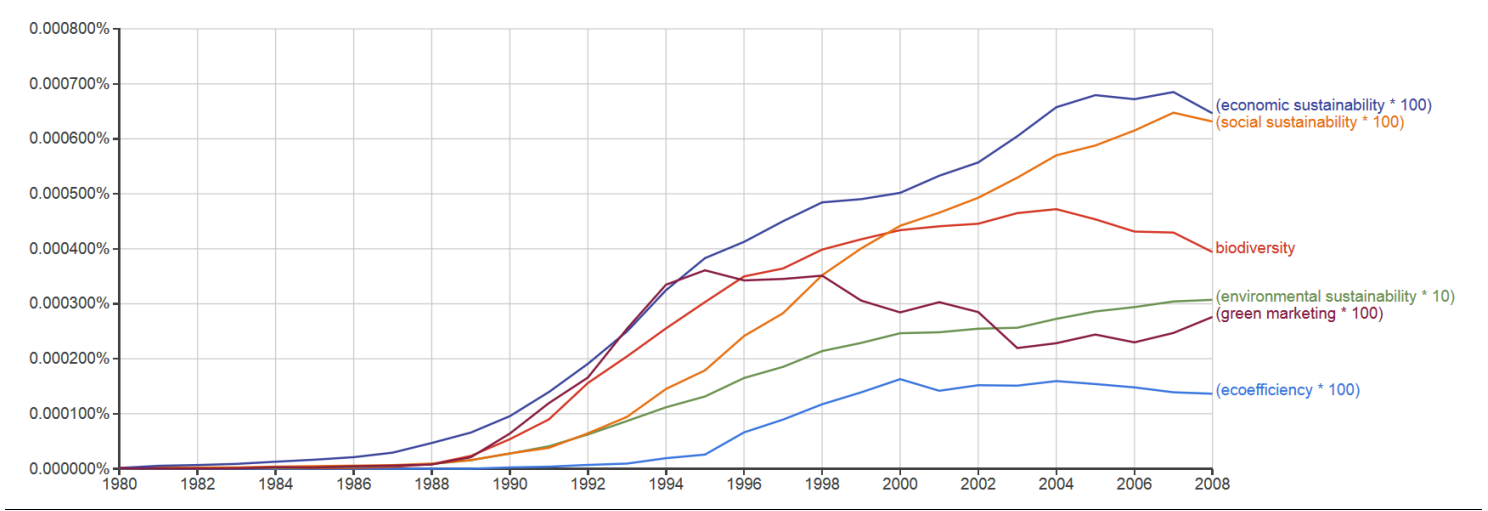

Figure 5: Variation of Terms Emerging From 1980 to 1990 Over Time

The graph for the terms emerging after 1980 can be seen in Figure 5. This graph also displays that not only emergence dates of terms, but also their frequencies of being encountered in the literature over years show similar variations. Biodiversity is the term with the highest rate of encountering and environmental sustainability needed to be multiplied by 10 in order to be legible; while economic sustainability, social sustainability, green marketing and eco-efficiency terms needed to be multiplied by 100 . The rapid increase, seen in the frequencies of all terms from 1988 to 1990, continued with a decline in the following years. The facts that these terms have very close dates of emergence in the literature and that their variations over years are so similar hint that the terms are closely associated.

It is seen on the graph that the emergence dates of the three dimensions of corporate sustainability (economic, environmental, social) in the literature are post1980. This can be associated with the Brundtland Report published in 1987. It is seen that the amount of increase of environmental sustainability is higher than the remaining two dimensions. It is possible to attribute this increase in 'environmental sustainability' to the progression of sustainable development as fundamentally an environmental approach since Carl Von Carlowitz (1713). 'Green marketing' and 'eco-efficiency' can be identified as the least researched terms as their frequencies were very low and their emergence dates were later than other terms. 


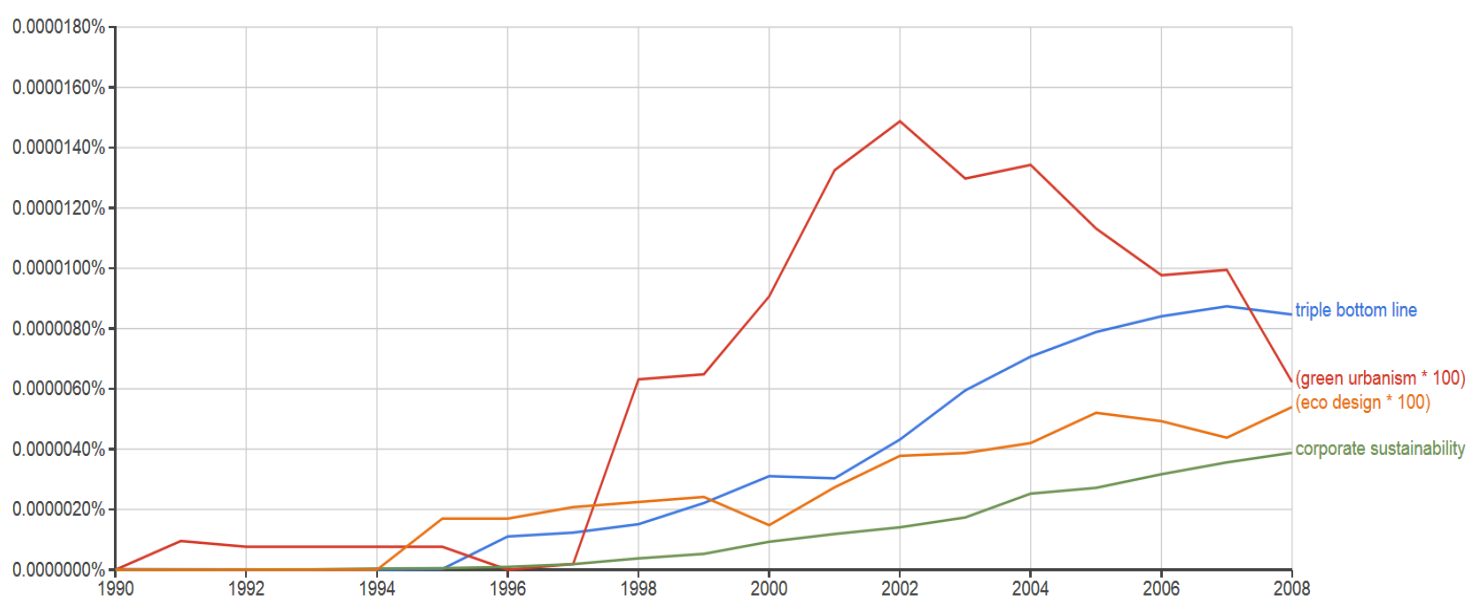

Figure 6: Variation of Terms Emerging After 1990 Over Time

The similarity of curves formed in relation to the mentioning rates of triple bottom line, eco design and corporate sustainability terms, which emerged after 1990, in the literature over years. Among these terms, the variation of eco design is quite parallel with triple bottom line and corporate sustainability, although it is mentioned 100 times less than these terms. In this respect, eco design and green urbanism were reflected in the graph by being multiplied by 100 in order to obtain a more legible graph. Eco design and corporate sustainability displayed an upward trend in 2000 s, while green urbanism declined from 2002 to 2008 .

The stable increase of corporate sustainability and triple bottom line by years in 2000s is particularly remarkable. Triple bottom line gained popularity with the book of John Elkington (1997) titled "Cannibals with Forks: The Triple Bottom Line of 21st Century Business", and made a leap during late 1990s as it can be seen in the graph (Henriques and Richardson, 2004). The sense of sustainable development (Bruntland, 1987) and triple bottom line in 1990s (Elkington, 1997) took control of negative effects on economic factors, natural resources and social structure, thus having an impact in the prevalence of corporate social responsibility applications. This expansion in administration and corporate responsibility assisted in the development of the sense of corporate sustainability by the end of 1990s (Young and Tilley, 2006: 403).

While three terms display quite similar simultaneous variations in this graph, only green urbanism is separated from them. While the relationship of these three terms can be analyzed further, green urbanism should be addressed separately within the scope of sustainable development and analyzed with different terms although it emerged in the literature around the same dates as the others.

\section{Conclusions and Suggestions}

Many international organizations such as the United Nations, OECD and G20 agree that growing problems such as climate change, depletion of natural resources and human rights violations should be immediately solved for long term development and stability, and that the solution will be possible by means of an increase in environment, social and corporate governance applications of companies. This awareness helped sustainability literature grow and develop over time. This study attempted to establish the change undergone by corporate sustainability and associated fundamental terms in 
the historical process. As a result of conducted analysis, it was determined that corporate sustainability and many associated terms emerged or their repetition frequencies increased post-1980s. But never in the world's history has there been a more drastic growth in production, consumption and wealth than after the Industrial Revolution. In the period between 1800 and 1970, when the world's population tripled from around 978 million to 3632 million, seemingly unslackened economic growth occurred and the quantity of manufacturing production in the world increased about 1730 times ( $\mathrm{Du}$ Pisani, 2007: 87). In this time period the negative environmental changes due to the increasing production and population resulted with the popularity of some terms about the environmental aspect of sustainable development such as 'recycle', 'waste management' and 'environmental management'. We can observe that in 1980's another environmental sustainability concept like 'biodiversity' has show up and the studies around this concept started to rise. After 1990 with the Our Common Future (Brundtland Report) published in 1987 corporate sustainability and triple bottom line concepts seem to occur more frequently. In the period following publication of the report, the interest of business world and academics in the subject rapidly increased as it can be seen in N-gram analyses. However, it should be noted that emergence dates and development courses of social development and environmental development terms, which played a role in emergence and development process of sustainable development and corporate sustainability, are remarkable. It is seen that particularly social development, which dates back to $1800 \mathrm{~s}$, is used by certain anthropologists and sociologists (W.G. Sumner, H. Spencer and J. Hobhouse), outside the context of sustainability (Midgley, 2013: 5).

In the study, it was seen that private sector employees, whose opinions on terms regarding corporate sustainability were received, emphasized terms such as urbanization, population planning, industrialization on correct land, and effective management of natural resources; while academics attributed more significance to terms such as organization culture, corporate social responsibility, green marketing, and eco efficiency. This shows that sector employees address corporate sustainability in a much more macro level than academics; in other words, as sustainable development.

This can be explained by the legal regulations, export-import policies as well as pressure from the public and non-governmental organizations encountered by private sector employees on a national and international scale. It is important for academics conducting studies, public sector and other interested parties to draw the framework of corporate sustainability and completely identify the limits of the subject. This shows that there is need for much more research addressing the term. Furthermore, emphasis should be placed also on the provision of trainings, intended for raising sustainability awareness, to all interested parties.

Conducting different studies on terms that historically display simultaneous variations, as well as the terms that are differentiated from them, using data and findings provided by this study might be helpful in a more accurate determination of the places of these terms and their meanings within corporate sustainability. Thus, making a more accurate sense of corporate sustainability and its sub-terms is expected to contribute significantly to both the researchers and the implementers.

Because this study has been conducted with the data gathered from only a small group of academicians and field workers, suggestions the search phrases were limited 
with their point of view. Further studies can be carried with different search phrases from the literature. Besides other stake holders opinions can also be used by determining the search phrases.

The search phrases have been analyzed on books.google.com. Other platforms are also available for searching the same phrases. With the data from different sources it could be possible to compare the results.

This study is based on N-gram analysis. Other content analysis methods are also possible about the subject. Besides not only written sources but also audio visual sources and other materials can be analyzed to determine the concept and sub terms on sustainability. This will reveal the real meaning of those terms more precisely.

\section{References}

Aguilera, R.V. \& Cuervo-Cazurra, A. (2004). Codes of Good Governance Worldwide: What is the Trigger?, Organization Studies, Vol.25, Issue: 3, pp.417-446.

Besler, S. (Ed.) (2009). Yönetim Yaklaşımlarıyla Kurumsal Sürdürülebilirlik, Beta, İstanbul.

Braunerhjelm, P. \& Hamilton, U.S. (2012). Social Entrepreneurship - A Survey of Current Research, Working Papers Series from Swedish Entrepreneurship Forum, Working Paper: 19.

Carson, R. (1962). Silent Spring, Greenwich: Fawcett Publications Inc.

Crane, A. (2000). Corporate Greening as a moralization, Organization Studies, Vol.21/4.

Du Pisani, J.A. (2007). Sustainable Development - Historical Roots of the Concept, Environmental Sciences, Vol.3, Issue: 2, pp.83-96.

Ehrlich, P.R. (1968). The Population Bomb, Sierra Clup /Ballantine Book, p.201.

Elkington, J. (1997). Cannibals with Forks: The Triple Bottom Line of 21st Century Business, Oxford: Capstone Publishing.

G. H. Bruntland, (1987). Our Common Future, Oxford University Press: Oxford.

González-Benito, J. \& González-Benito, Ó. (2006). A Review Of Determinant Factors Of Environmental Proactivity, Business Strategy and The Environment, Volume 15, Issue 2, March/April, pp.87-102.

Griffin, J.\& Mahon, J. (1997). The Corporate Social Performance and Corporate Financial Performance Debate: Twenty-Five Years of Incomparable Research, Business and Society, 36/1, pp.5-31.

Hahn, T. \& Scheermesser, M. (2006). Approaches to Corporate Sustainability Among German Companies, Corporate Social Responsibility and Environmental Management, vol.13.

Haris, J. (2000). Basic Principles of Sustainable Development, Global Development and Environment Institute Working Paper, No. 04. 
Haugh, H.M. \& Talwar, A. (2010). How Do Corporations Embed Sustainability Across the Organization?, Academy of Management Learning \& Education, Vol. 9 Issue 3, pp.384-396.

Henriques, A. \& Richardson, J. (2004). Triple Bottom Line : Does It All Add Up?: Assessing the Sustainability of Business and CSR, London.

Manning, C. \& Schütze, H. (1999). Foundations of Statistical Natural Language Processing, MIT Press, ISBN 0-262-13360-1, Cambridge, USA.

Meadows et.al.(1972). The Limits to Growth, Universe Books, First Edition Cover, p.205.

Midgley, J. (2013). Social Development Theory and Practice, University of California Berkeley.

Moura-Leite, R.C.\& Padgett, R.C. (2011). Historical Background of Corporate Social Responsibility, Social Responsibility Journal, Vol. 7, Issue: 4, pp.528-539.

Muscoe, M. (1995) A Sustainable Community Profile, Places Journal, Vol. 9, Issue 3.

Norgaard, R. B. (1994). Development Betrayed: The End of Progress and a Coevolutionary Revisioning of the Future, Routledge, New York and London.

Ponting, C. (2008). A Green History of the Word, The Environment and the Collapse of Great Civilizations, Penguin Books.

Porter, P. W. \& Sheppard, E. S. (1998). Views form the Periphery: Encountering Development. A World of Difference: Society, Nature, Development. (Eds.P. W. Porter and E. S. Sheppard). Guilford Press, New York.

Repetto, R. (1986). World Enough and Time: Successful Strategies for Resource Management, Yale University Press.

Stanwick P. \& Stanwick, S. (1998). The Relationship Between Corporate Social Performance, and Organizational Size, Financial Performance, and Environmental Performance: an Empirical Examination, Journal of Business Ethics, 17/2, pp.195-204.

Streeten, P. et al. (1981). First Things First: Meeting Basic Human Needs in the Developing Countries. Published for the World Bank, Oxford University Press, New York and Oxford.

Tiryakioğlu, M.\& Tuna, Ö. (2016). Kalkınma Ajanslarının Çevresel Sürdürülebilirliği Sağlamadaki Rolü Üzerine Bir Tartışma, Süleyman Demirel Üniversitesi İktisadi ve İdari Bilimler Fakültesi Dergisi, Y.2016, C.21, S.1, pp.207-221.

Tuna, Ö. (2014). Corporate Sustainability Approaches And Practices: The Study on SMEs, Afyon Kocatepe University, The Institute of Social Sciences Department of Management, $\mathrm{PhD}$ Thesis, Ocak.

Türkiye Sanayici ve İş Adamları Derneği (TUSİAD) (2009). Dünyada ve Türkiye'de İş Etiği ve Etik Yönetimi, Yayın No: TÜSİAD/T-2009-06-492, www.tusiad.org 
Ural M. N. \&Tuna, Ö. (2015). The Analysis of Basic Concepts Related to Corporate Sustainability by Using N-Gram Analysis Technique, International Conference on Sustainable Development (ICSD), pp.153-158.

Vitousek et.al. (1986). Human Appropriation of the Products of Photosynthesis, BioScience, Vol. 36, No. 66, pp. 368-373.

Waddock, S.\& Graves, S. ( 1997). "The Corporate Social Performance-Financial Performance Link", Strategic Management Journal, 18/4, pp.303-319.

Young W. \&Tilley, F. (2006). Can Businesses Move Beyond Efficiency? The Shift Toward Effectiveness And Equity in The Corporate Sustainability Debate, Business Strategy and the Environment, Volume 15, Issue 6, pp. 402-415. 